\title{
ECONOMICAL BEHAVIOR ANALYSIS OF AGRICULTURAL COMPANIES IN IRAQ USING TRANSLOG COST FUNCTION
}

Z. A. G, AJ-Jiboory

Researcher

Dept.of Agricultural Economy - College of Agriculture -University of Baghdad

blue_sky1554@yahoo.com
E. H. Ali

Assist.Prof eskanderhali81@gmail.com

\section{ABSTRACT}

This research aims to identify the productive relationship nature among the elements used in the agricultural companies by estimating the translog cost function. It also aims to recognize the possibility of substituting these elements with each other, to identify the nature of revenues, and economies scale through elasticity of other cost. This research goes further to define the typical use of resources, identify the performance of the companies and their contribution in controlling their cost, and estimating elasticity of substitution (Allen-Uzawa), (Morishima). The translog cost function was estimated so as the total cost of the agricultural companies is a function of the prices of production and production quantity output elements. The shares of production elements (labor, capital, commodity and services requisites) were derived from this translog cost function by using SUR method and Eviews9 after applying symmetry and homogeneity. It was clear, in the translog cost function or in the production elements share functions, that there is a strong correlation between the prices of the production elements and the total costs. If prices increase, their contribution share in the total costs increases. Calculation were made among production elements, the self demand, cross, and substitution elasticity. Results show that the self demand was $(0.02 \cdot 2.28$ ، $0.64 \cdot 2.01)$. This result clarifies the share of the production elements (labor, capital, commodity and services requisites) in the total costs of the agricultural companies. The results show that increasing in the wage of labor, capital prices, and commodity and services requisites with $1 \%$ had led to increase in the demand on labor, capital prices, and commodity and services requisites with $(\mathbf{0 . 6 4 \% , 2 . 1 0 \%}$, $\mathbf{0 . 0 2 \%}$, and $\mathbf{2 . 2 8 \%}$ ) respectively. The elasticity (Allen - Uzawa) of partial substitution between the labor and capital was 0.0009 . This indicates that increasing the capital price value to the labor wage with rate of $1 \%$ will decrease the capital element rate to the labor wage with $0.0009 \%$. This is a very low rate. The elasticity of partial substitution (Morishima) for the elements of production shares was $(2.1,0.02,2.27$, and 0.06$)$.

Key words: Elasticity (Allen-Uzawa, Marishima), Elements of production shares, Zillner repition method. *Part of M.Sc.thesis of the $1^{\text {st }}$ other

الجبوري وعلي

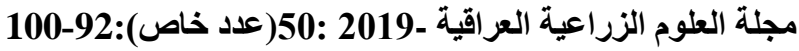

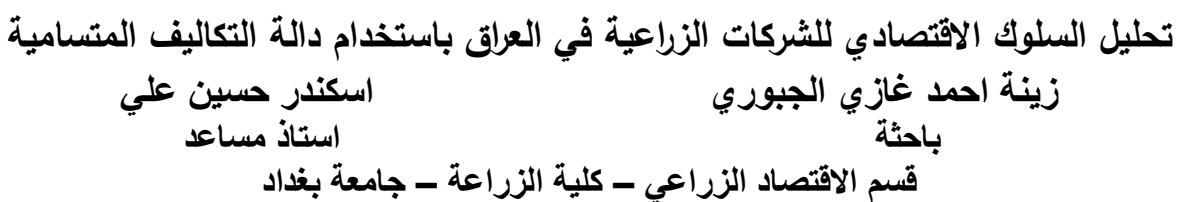

| (لمستخلص

يهدف البحث الى التعرف على طبيعة العلاقة بين العناصر الانتاجية المستخدمة في الثركات الزراعية من خلال تقدير دالة التكاليف المتسامية ومعرفة امكانية احلال هذه العناصر محل بعضها البعض والتعرف على طبيعة عوائد واقتصاديات الحجم من خلال مرونات التكاليف الاخرى ـ وتحديد الاستخدام

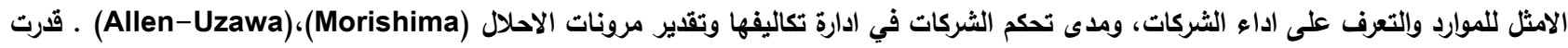
دالة التكاليف المتسامية بحيث كانت الكلفة الكلية للشركات الزراعية دالة لاسعار عناصر الانتاج والناتج واثثتق منها حصص عناصر الانتاج (العمل ، راس المال ، المستلزمات السلعية ، المستلزمات الخدمية ) باستخدام طريقة SUR ويرنامج eveiws9 بعد تطبيق شروط التماثل والتجانس، . وتبين ان

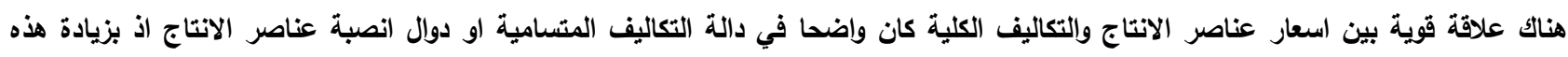

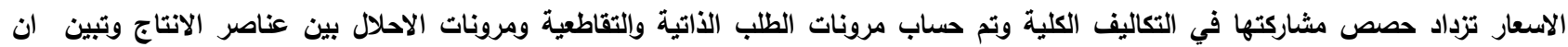
المرونات الذاتية بلغت ( 0.64،2.01 ، 0.02،28) و هذا يوضح حصة عناصر الانتاج في التكاليف الكلية للثركات الزراعية (العمل،راس

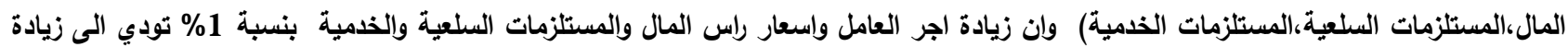

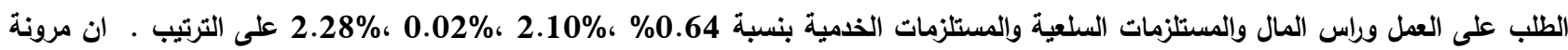
Allen-uzawa

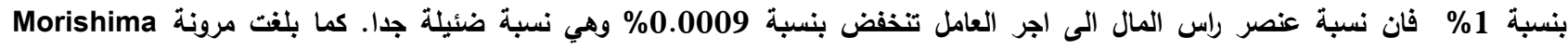

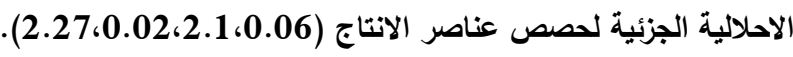
الكلمات المفتاحية : مرونة (Allen-Uzawa،Marishima))، حصص عناصر الانتاج , طريقة زلنر التكرارية .

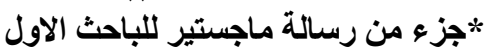




\section{INTRODUCTION}

Several studies have been done to handle the restrictions of the Cobb-Douglas function by deriving supply and demand equations from production functions and defining the necessary condition for the balance between the production and what resulted from them concerning measuring the elasticity of substitution among inputs by production and cost theories through the productivity among inputs. This is what Frish did in 1935. Later on, arrow tried to find the substitution rate among production elements and to have an implied function for the production and then the constant elasticity of substitution production function appeared(1). Then, Hendy used the Ordinary Least quares (OLS) to estimate the relation between the production and its elements. Hendy with his colleague, Dillon, also tried using the Random Limits Function of Second-degree random in logarithmic form. These and other attempts have led to other forms and functions. The most distinguished one was the high cost function. The costs function in economical analysis for demand inputs and substitution elements is considered as a good example for the strong relation between the economical theory and the standard economy. In 1935, Ranger Frish used the measuring of elasticity of substitution among inputs in the production and costs theory by the marginal productivity between inputs (2). The production function expresses the mathematical and geometrical relation between production inputs and their outputs. There were many forms for this function which could be used. One of them is the Cobb-Douglas function, which is used to estimate production functions and depositing size revenues.This function lacks the assumption that the elasticity of substitution of production elements should equal one integer. This means that it is a homogeneous function of greater or smaller than one. If the elasticity is greater or smaller than one, the function will be biased upwards.Then, there should be inaccurate statistical results. That is why many studied have been done to handle the restrictions of the Cobb-Douglas function by deriving supply and demand equations from production functions and defining the necessary condition for the product balance.
Therefore, other functions have been chosen, including the high logarithmic function by Christen and Jorgenson (3). Many studies have leaned to use the logarithmic high cost function. They called it in short Translog. It is widely used today in standard studies to observe product behavior and to verify the nature of the substitution process between production elements and the nature of the demand functions of production elements. The Translog is an extension of the logarithmic Taylor series (4). This model does not limit the elasticity of substitution. It is characterized with the fact that elasticity of substitution is changed whenever there is a change in elements of production. Translog also permits the marginal output to be increased before the final decrease of the function. This is due to an elastic function and permits the multiple inputs and outputs and does not assume any restrictions on elasticity of substitution, economies of scale and range. It resembles the total cost decrease model (5). One of the benefits of this function is that it measures the elasticity of demand of the price and cross. It also measures the elasticity of substitutions between the production elements. The function is characterized with elasticity. It leads to variable values of elasticity in contrast with the other traditional functions. Translog is one of the widest and the best spread function forms. The general form of the cost function is (17).The importance of agricultural companies comes from the role they could play, especially with the increase of gap in food and some other basic commodity due to the lack of agricultural production. This issue should be a reason to encourage for the investment, which is witnessing a cute decline in the agricultural sector. It is necessary to promote the agricultural companies through organizing a comprehensive policy plan that take the initiative of being the motive for the companies in enhancing the development of the agriculture sector. This could be put into force by applying the rules and requirement of the market economy (11).Measuring the efficiency and capability of the companies to continue its economical activities is of high importance. The problem of research is in the inefficiency of agricultural companies and in their role in understanding the nature of the 
relationship between production elements. This research aims to identify the productive relationship nature among the elements used in the agricultural companies by estimating the translog cost function. It also aims to recognize the possibility of substituting these elements with each other, to identify the nature of revenues, and economies scale through elasticity of other cost. This research goes further to define the typical use of resources, identify the performance of the companies and their contribution in controlling their cost, and estimating elasticity of substitution (AllenUzawa), (Morishima) (10).

\section{MATERIALS AND METHODS}

The data is taken from the research sample of the six agricultural companies registered in the Iraqi Stock Exchange as follows:

1. The Private company for agriculture production

2. The Iraqi company for production and marketing of agricultural products.

3. The Iraqi company for production and marketing meat and farm crops.

4. The Iraqi company for seeds production.

5. The modern company for the agriculture production.

6. Middle East company for fish production.Other data related sources were taken for the period from 2005 to 2016.

The research method will use the translog cost function that is widely used today in the standard studies to study the behavior of the facility to verify the nature of the substitution between the inputs and the nature of the demand functions on the production elements.

\section{RESULTS AND DISCUSSION}

several studies have leaned to use the logarithmic translog cost function, which is called in short Translog.

It is widely use today in standard studies to observe product behavior and to verify the nature of the substitution process between production elements and the nature of the demand functions of production elements. The Translog is an extension of the logarithmic Taylor series. This model does not limit the elasticity of substitution. It is characterized with the fact that elasticity of substitution is changed whenever there is a change in elements of production. Translog also permits the marginal output to be increased before the final decrease of the function. This is because it is an elastic function and permits the multiple inputs and outputs and does not assume any restrictions on elasticity of substitution, economies of scale and range. It resembles the total cost decrease model. One of the benefits of this function is that it measures the price and cross elasticity of demand of the price and cross. It also measures the elasticity of substitutions between the production elements. The function is characterized with elasticity. It leads to variable values of elasticity in contrast with the other traditional functions. Translog is one of the widest and the best spread function forms. The general form of the cost function is (12).

\section{$\mathbf{T C}=\mathbf{f}(\mathbf{p i}, \mathbf{y}) \ldots . \mathrm{Z}$}

This function represents the relationship between the lowest cost and a certain level of production under the given prices. According to the economic theory, the costs function in the $\mathrm{z}$ equation has the familiar characteristics of being a continuous ,its have first and second partial derivations and it is a non-decreasing an homogeneous of degree one in prices and can be rewritten in the logarithmic form (6).

Ln c=g (In pi, In y)+ei..... $Z_{1}$

Ln C: It is a logarithmic costs function, such as the total cost allocation process to the minimum limit. The actual total cost cannot be less than the planned cost. The difference between them represents the random disturbance.

\section{$\mathbf{E i}=\mathbf{v i + u i}$}

ui: represents cost-ineffective, expresses the amount of deviation of the actual cost of the facility frmo its typical level, following a halfnormal distribution. vi: represents random error and it is subjected to the normal distribution. After applying the Taylor series on the function $\mathrm{Z}_{1}$ we get a high costs function for the agricultural companies.We will estimate the translog costs function of the and the shares of production elements involved in the productive process with the application of symmetry and homogeneity restrictions. Due to the fact that the cost function must show homogeneity of degree one in the prices of production elements, the constraints are necessary and sufficient for the condition of 
linear homogeneity in prices of the production elements. We have :

$\sum_{\mathrm{j}=1}^{\mathrm{n}} \mathbf{B}_{\mathrm{j}}=\mathbf{0}$

$\sum_{\mathrm{i}=1}^{\mathrm{n}} \mathbf{B}_{\mathrm{ij}}=\mathbf{1}$

$\sum_{\mathrm{j}=\mathbf{1}}^{\mathrm{n}} \mathbf{y}_{\mathrm{ij}}=\mathbf{0}$

Where :

$$
\mathrm{J}=(\mathbf{L}, \mathbf{k}, \mathbf{m}, \mathbf{s}) \text { । I = (1,2,3,4, })
$$

$$
\begin{gathered}
S L=C_{1}+C_{2} L N W+C_{3} L N R+C_{4} L N M+C_{5} L N S \\
S K=C_{6}+C_{7} L N W+C_{8} L N R+C_{9} L N M+C_{10} L N S \\
S m=C_{11}+C_{12} L N W+C_{13} L N R+C_{14} L N M+C_{15} L N S \\
S s=C_{16}+C_{17} L N W+C_{18} L N R+C_{19} L N M+C_{20} L N S
\end{gathered}
$$

These derived functions are called translog costs share equations .

Where:

SL : represents the labor element share calculated from labor element value divided by the whole total cost .

SK: represents the capital element share calculated from capital value divided by the whole total costs.

$\mathrm{SM}$ : represents commodities requisites element share calculated by commodities requisites divided by the whole total costs. SS: represents service requisites element share

$$
\begin{gathered}
S L=C_{1}+C_{2} L N W+C_{3} L N R+C_{4} L N M \\
S K=C_{5}+C_{6} L N W+C_{7} L N R+C_{8} L N M \\
S M=C_{9}+C_{10} L N W+C_{11} L N R+C_{12} L N M
\end{gathered}
$$

As long as the restrictions include the symmetry and homogeneity, the matrix 1 should be taken f.e or these derivations as in the following:

$\left[\begin{array}{lll}C_{11} L N W & C_{12} L N R & C_{13} L N M \\ C_{21} L N W & C_{22} L N R & C_{23} L N M \\ C_{31} L N W & C_{32} L N R & C_{33} L N M\end{array}\right]$

Where $\mathrm{C} 3$ is symmetrical to $\mathrm{C} 6, \mathrm{C} 4$ is symmetrical to $\mathrm{C} 10$, and $\mathrm{C} 8$ is also symmetrical to $\mathrm{C} 11$. So the derivation would be written as follows.

$$
\begin{aligned}
& S L=C_{1}+C_{2} L N W+C_{3} L N R+C_{4} L N M \\
& S K=C_{5}+C_{3} L N W+C_{6} L N R+C_{7} L N M \\
& S M=C_{8}+C_{4} L N W+C_{7} L N R+C_{9} L N M
\end{aligned}
$$

Estimating the last raw i.e the forth and the forth column i.e the parameters of the service requisites share function will be done after estimating the function depending on the homogeneity condition :-

$$
\begin{aligned}
& C_{1}+C_{5}+C_{8}+C_{10}=1 \\
& C_{i i}+C_{j j}+C_{m m}+C_{s 5}=0
\end{aligned}
$$

calculated by service requisites divided by the whole total costs Because the translog costs function, whether it is restricted or nonrestricted, requires three equations only, the first three shares had been taken. They are, the labor, the capital, and the commodities requisites. Each share had been divided by the service requisites i.e SS/SL, SS/Sk, SS/Sm. Then, there should be equation system for the high logarithmic shares under a first degree symmetry and homogeneity restrictions in prices and in using constant revenues scale. The form of this system is as follows:-

After that, share functions will be formed from the Seemingly Unrelated Regression Function (SURE) . They are related with each other within the random error limits across the three equations. The type of this connection is synchronized one. Thus, the model had been estimated by the repeated SURE model for the system under the symmetry and homogeneity restriction (14) by using Eviews program Table 1. 
Table 1.shares of production elements.

\begin{tabular}{|c|c|c|c|c|}
\hline \multicolumn{5}{|c|}{$\begin{array}{l}\text { System: UNTITLED } \\
\text { Estimation Method: Seeminply Unrelated Repression } \\
\text { Date: } 06 / 12 / 18 \text { Time: } 09.06 \\
\text { Sample: } 20052016 \\
\text { Included observations: } 72 \\
\text { Total system (batanced) observetions } 216 \\
\text { Linear estimation after one-step weighting matrix }\end{array}$} \\
\hline & Coefficient & Std. Error & t-Statestic & Prob. \\
\hline$C(1)$ & 0.581746 & 0.028340 & 20.52754 & 0.0000 \\
\hline$C(2)$ & 0.040025 & 0.000999 & 40.06943 & 0.0000 \\
\hline $\mathrm{C}(3)$ & 0.001188 & 0.007233 & 0.164226 & 0.8697 \\
\hline$C(4)$ & -0.016857 & 0.000822 & -20.25399 & 0.0000 \\
\hline$C(5)$ & -1.189181 & 0.220282 & -5.398454 & 0.0000 \\
\hline$C(6)$ & 2.101944 & 0.257046 & 8.177317 & 0.0000 \\
\hline$c(7)$ & -0.008554 & 0.003570 & -2.395995 & $\begin{array}{l}0.0175 \\
0.0000\end{array}$ \\
\hline$C(8)$ & 0.621856 & 0.029534 & 21.05576 & 0.0000 \\
\hline$C(9)$ & 0.038164 & 0.000880 & 43.38549 & 0.0000 \\
\hline \multicolumn{2}{|c|}{ Determinant residual covariance } & 8.33E-11 & & \\
\hline \multicolumn{5}{|c|}{$\begin{array}{l}\text { Equation: } \mathrm{SL}=\mathrm{C}(1)+\mathrm{C}(2) * \mathrm{LNW}+\mathrm{C}(3) \cdot \mathrm{LNR}+\mathrm{C}(4) * \mathrm{LNM} \\
\text { Qbsernations: } 72\end{array}$} \\
\hline R-squared & 0.665963 & \multicolumn{2}{|c|}{ Mean dependent var } & 1.025198 \\
\hline Adjusted R-squared & 0.651227 & \multicolumn{2}{|c|}{ S.D. dependent var } & 0.042899 \\
\hline S.E. of reqression & 0.025335 & \multirow{2}{*}{\multicolumn{2}{|c|}{ Sum squared resid }} & 0.043646 \\
\hline Durbin-Watson stat & 0.754573 & & & \\
\hline \multicolumn{5}{|c|}{$\begin{array}{l}\text { Equation: } S K=C(5)+C(3) * L N W+C(6) * L N R+C(7) * L N M \\
\text { Obsenvations: } 72\end{array}$} \\
\hline R-squared & 0.496025 & \multicolumn{2}{|c|}{ Mean dependent var } & 0.991438 \\
\hline Adjusted R-squared & 0.473791 & \multirow{2}{*}{\multicolumn{2}{|c|}{$\begin{array}{l}\text { S.D. dependent var } \\
\text { Sum squared resid }\end{array}$}} & 0.079060 \\
\hline S.E. $\alpha$ regression & 0.057351 & & & 0.223657 \\
\hline Durbin-Watson stat & 1.632326 & & & \\
\hline \multicolumn{5}{|c|}{$\begin{array}{l}\text { Equation: } S M=C(8)+C(4) * L N W+C(7) * L N R+C(9) * L N M \\
\text { Oeservations: } 72\end{array}$} \\
\hline R-squared & 0.917943 & \multirow{4}{*}{\multicolumn{2}{|c|}{$\begin{array}{l}\text { Mean dependent var } \\
\text { S.D. dependent var } \\
\text { Sum squared resid }\end{array}$}} & 0.990600 \\
\hline Adiusted R-squared & 0.914323 & & & 0.095317 \\
\hline S.E. d reqression & 0.027900 & & & 0.052931 \\
\hline Durtin-Watsan stal & 0.596613 & & & \\
\hline
\end{tabular}

Source: by the researcher with Eviews9 program.

Table 1 shows shares participation function of labor, capital and commodity requisites. These factors are with positive sign and correspond to the logic of the economical theory. The values of the determining factor indicates that there is a strong relation between commodity requisites, labor prices and capital prices. The value of coefficient of determination $\boldsymbol{R}^{2}$ to the labor share element 0.66 . This is a high value in this costs function. This is in compare to the previous function where the relationship was weak between the total cost function and the labor function with 0.30 . This may be attributed to the equation systems and to the repeated Zillner method. Concerning the shares of capital production element the value was $0.49=\boldsymbol{R}^{2}$ between total costs and the capital share which was 0.61 . This decline is due to the fact that the capital share is the labor wages prices and commodity requisites, services requisites, taxes, and losses.The declines was also because labor wage was as a dependent variable and the commodities and service requisites were taken separately.This is because the restricted high costs, as mentioned before, need the relation between variables and not with the total costs function. This procedure causes decreasing in the total of the capital value. The determining factor $\boldsymbol{R}^{2}$ of the commodity requisites function was high 0.91 , which indicates the strength of the relationship between the factors of this element. The illustrative variables interpreted $91 \%$ of the dependent labor share and $9 \%$ of the other variables that are not included in the model and its effect was absorbed by the random variable. And $\mathrm{D}-\mathrm{W}$ values were for the three functions $(0.59,1.63,0.75)$, respectively. The production elements contribution shares functions show the sense of the factor functions except for the $\mathrm{C} 7$ and C3. Although the sense in the high costs functions is relatively unimportant because what is important is to obtain the function factors and use them to calculate cross-price demand and substitution elasticity. The results of these functions also indicated that the increase of labor wage with $1 \%$ the labor share will increase will increase by $0.04 \%$. The increase in the capital price by $1 \%$ increases the capital share of the total costs by $2.1 \%$. The increase in the commodity requisites value by $1 \%$, the share of these requisites will increase by $0.03 \%$. The arithmetic averages were used for the actual values of the production element shares were used with the extracted factors from the production element shares cost functions listed in Table 36 and shown in Matrix 2 in the calculation of demand elasticity and substitution elasticity, as follows:

$\left[\begin{array}{cccc}0.04 & 0.001 & -0.01 & -0.031 \\ 0.001 & 2.1 & -0.008 & -2.09 \\ -0.01 & -0.008 & 0.03 & -0.032 \\ -0.031 & -2.09 & -0.032 & 2.15\end{array}\right]$

We have to refer here to the symbols of the equations to be used in later on and they are as in the following:

$\boldsymbol{\varepsilon}_{\mathrm{ii}}$ : represents own price demand elasticity of the labor element.

$\boldsymbol{\varepsilon}_{\mathrm{jj}}$ : represents own price demand elasticity of the capital element.

$\varepsilon_{m m}$ : represents own price demand elasticity of the commodity requisites element.

$\varepsilon_{s s}:$ :represents own price demand elasticity of the service requisites element. 
B) $\boldsymbol{c 2 , c 6 , c 9}$ represent estimated labor from the logarithmic shares costs function

$S i$ : represent the arithmetic mean for the actual values of labor element share.

Sj : represent the arithmetic mean for the actual values of capital element share.

$S \boldsymbol{m}$. : represent the arithmetic mean for the actual values of commodity requisites element share.

\section{Own price elasticity of demand}

Alfred Marshall created the elasticity of demand concept, a measure used in economics to show the response rate or elasticity of the demanded quantity of the commodity or service to change its price (15). Self-elasticity measures the responsiveness of demand to this element as a result of changes in its marginal productivity, supposing that the other variables remain constant (19:

$S_{\mathrm{j}}=\frac{B i j+s i(s i-1)}{s i}=\frac{B i i}{s i}+s i-1$

\section{: Cross-elasticity}

The Cross-elasticity: the relationship among ( labor and capital), (labor and commodity requisites), and (capital and commodity requisites) is created in accordance with the following :

$\beta_{\mathrm{ij}}=\frac{\partial^{2} \operatorname{Ln} c}{(\partial \operatorname{Ln} p \mathrm{i})(\partial \operatorname{Ln} p \mathrm{j})}=\frac{\partial s_{\mathrm{i}}}{\partial \operatorname{Lnp}_{\mathrm{j}}}$

$\beta_{\mathrm{ij}}=\frac{\propto_{i j}+s_{i} s_{j}}{\mathrm{~s}_{\mathrm{i}}}=\frac{\propto_{i j}}{\mathrm{~s}_{\mathrm{i}}}+s_{j}$

The arithmetic means of the actual values of the production elements shares were used, with the factors extracted from the production elements shares cost functions, in calculating the partial elasticity of Allen and the demand elasticity of the high cost functions of the logarithmic shares. The elasticity of partial substitution among the production elements can be calculated. Uzual , 1962, proved that the elasticity of substitution used by Aleen 1938 could be written as the following two forms (1):

1- Allen-Uzawa partial Elasticity of Substiution (AES)

$\operatorname{Aes}_{i j}=\frac{\propto_{i j}+s i s j}{s i s j}$

$\mathbf{i} \neq \mathbf{j}$

2- Marishima Partial Elasticity of Substiution (MES)
$\operatorname{Mes}_{\mathrm{ii}}=\frac{\alpha_{\mathrm{ij}}+\mathrm{s}_{\mathrm{i}} \mathrm{s}_{\mathrm{j}}}{\mathrm{s}_{\mathrm{j}}}=\frac{\alpha_{\mathrm{ii}}+\mathrm{si}^{2}-\mathrm{s}_{\mathrm{i}}}{s_{j}} \quad, \mathrm{i} \neq j$

If there are more than two variables, it can be rewritten according to the following formula:

$\partial_{13}=\frac{\beta_{13}+s_{1} s_{3}}{s_{1} s_{3}}$

$\partial_{23}=\frac{\beta_{23}+s_{2} s_{3}}{s_{2} s_{3}}$

Own price Elasticity of demand cross elasticity and elasticity of substitution for all production elements (labor, capital, commodity requisites and service requisites) were calculated as shown in table 2 .

In table 2, we can see that the elasticity of the estimated OWN -production elements (labor, capital, commodity requisites and service requisites) express the content and pattern of own-substitution among production elements.

The elasticity of the positive own-production share refer that the value of the production element increases with its price increase and decreases with its price decrease. But if it is negative, then the value of the production element decreases with its price increase and increases with its price decrease . As long as the self-elasticity are positive as shows in Table $2(0.64 \cdot 2.01$ ، 0.02 2.28), then this clarifies the production elements share (labor, capital, commodity requisites and service requisites )in the total cost of the agricultural companies. The increasing in the wage of labor, capital prices, and commodity requisites with $1 \%$ leads to increase in the demand on labor, capital, and commodity and services requisites with ( $0.64 \%, 2.10 \%$, $0.02 \%$, and $2.28 \%$ ) respectively. This is due to the fact that the labor, capital and requisites are inherent to agricultural production It is also noted that the elasticity of demand for the labor and commodity requisites was low, which means that demand for them is inelastic. The elasticity of demand for capital and service requisites has been high and this means that the demand is elastic. The cross-demand elasticity between the capital and labor in the demand function on labor was about 0.99 , i.e the increase in the capital price by $1 \%$ increases the demand on labor by $0.99 \%$, and this illustrate that there is substitution relation. 
Table 2. Allen partial Elasticity and Elasticity of Demand and shares of production elements

\begin{tabular}{|c|c|c|}
\hline Value & Icons & Elasticity \\
\hline 0.64 & $\boldsymbol{\varepsilon}_{\mathrm{ii}}$ & Elasticity Demand Self of Labor \\
\hline 2.10 & $\varepsilon_{\mathrm{jj}}$ & Elasticity of Demand Self Capital \\
\hline 0.02 & $\varepsilon_{m m}$ & Elasticity of Demand Self commodity requisites \\
\hline 2.28 & $\varepsilon_{S S}$ & Elasticity of Demand Self Service Requisites \\
\hline 0.99 & $\boldsymbol{\varepsilon}_{i j}$ & $\begin{array}{c}\text { Elasticity of Demand Cross Between labor and Capital For Labor Demand } \\
\text { Function. }\end{array}$ \\
\hline 1.02 & $\boldsymbol{\varepsilon}_{j i}$ & $\begin{array}{c}\text { Elasticity of Demand Cross Between labor and Capital For Capital Demand } \\
\text { Function. }\end{array}$ \\
\hline 0.97 & $\varepsilon_{i m}$ & $\begin{array}{c}\text { Elasticity of Demand Cross Between labor and commodity requisites For Labor } \\
\text { Demand Function. }\end{array}$ \\
\hline 1.009 & $\varepsilon_{m i}$ & $\begin{array}{c}\text { Elasticity of Demand Cross Between labor and commodity requisites For } \\
\text { commodity requisites Demand Function. }\end{array}$ \\
\hline 0.87 & $\boldsymbol{\varepsilon}_{\text {is }}$ & $\begin{array}{c}\text { Elasticity of Demand Cross Between labor and Service Requisites For Labor } \\
\text { Demand Function }\end{array}$ \\
\hline 0.99 & $\varepsilon_{s i}$ & $\begin{array}{c}\text { Elasticity of Demand Cross Between labor and Service Requisites For Service } \\
\text { Requisites Demand Function. }\end{array}$ \\
\hline 0.98 & $\varepsilon_{j m}$ & $\begin{array}{c}\text { Elasticity of Demand Cross Between Capital and commodity requisites For } \\
\text { commodity requisites Demand Function. }\end{array}$ \\
\hline 0.98 & $\varepsilon_{j m}$ & $\begin{array}{c}\text { Elasticity of Demand Cross Between Capital and commodity requisites For } \\
\text { Capital Demand Function }\end{array}$ \\
\hline-1.2 & $\varepsilon$ & $\begin{array}{c}\text { Elasticity of Demand Cross Between Capital and Service Requisites For Capital } \\
\text { Demand Function }\end{array}$ \\
\hline-1.3 & $\varepsilon_{s j}$ & $\begin{array}{c}\text { Elasticity of Demand Cross Between Capital and Service Requisites For Service } \\
\text { Requisites Demand Function }\end{array}$ \\
\hline 0.86 & $\varepsilon_{m s}$ & $\begin{array}{c}\text { Elasticity of Demand Cross Between commodity requisites and Service } \\
\text { Requisites For commodity requisites Demand Function }\end{array}$ \\
\hline 0.95 & $\varepsilon_{s m}$ & $\begin{array}{c}\text { Elasticity of Demand Cross Between commodity requisites and Service } \\
\text { Requisites For Service Requisites Demand Function }\end{array}$ \\
\hline 0.0009 & $\delta_{i j}$ & Allen partial Elasticity Btween Labor and Capital \\
\hline 0.015 & $\delta_{\mathrm{im}}$ & Allen partial Elasticity Btween Labor and commodity requisites \\
\hline 0.96 & $\delta_{\text {is }}$ & Allen partial Elasticity Btween Labor and Service Requisites \\
\hline 0.01 & & Allen partial Elasticity Btween Capital and commodity requisites \\
\hline-1.3 & & Allen partial Elasticity Btween Capital and Service Requisites \\
\hline 1.03 & & Allen partial Elasticity Btween commodity requisites and Service Requisites \\
\hline 0.06 & & Elasticity Mes for Labor Share Function \\
\hline 2.1 & $\delta_{i j}$ & Elasticity Mes for Capital Share Function \\
\hline 0.02 & $\delta_{\mathrm{mm}}$ & Elasticity Mes for commodity requisites Share Function \\
\hline 2.27 & $\delta_{5 s}$ & Elasticity Mes for Service Requisites Share Function \\
\hline
\end{tabular}

Source:Collected and Calculated By Researcherd Based on Equation of Demand and Substitutio Elasticites

The cross-elasticity demand between labor and capital in the demand function on the capital element was about 1.02. This means there is a substitution relation between the capital and labor. The cross-demand elasticity between labor and commodity requisites in the demand on labor function was 0.97 . This means that the increase in commodity requisites by $1 \%$ will lead to increase the demand on labor by 97\%. But the cross-demand elasticity between labor and commodity requisites of demand function on commodity requisites was 1.009 . This means the $1 \%$ increase in labor leads to increase the commodity requisites by $1.009 \%$.
The cross - demand elasticity between labor and service requisites of the demand on labor function was 0.87 . This means that $1 \%$ increase in labor leads to increase the commodity requisites by $0.87 \%$. The cross demand elasticity between labor and service requisites of the demand on service requisites function was 0.99 . This means that $1 \%$ increase in labor leads to increase the commodity requisites by $0.99 \%$. The cross demand elasticity between the capital and commodity requisites of the demand requisites function and demand capital function was with dame ratio 0.98 . This means that $1 \%$ increase 
in labor leads to increase the commodity requisites by $0.87 \%$. This is related to the idea that if there is an increase in one of the elements of $1 \%$, this will lead to an increase of the other element. This is also clear when the capital is available and increasing the companies will increase the commodity requisites they needed. The cross-demand elasticity between the capital and the service requisites of the demand on capital function was - 1.2. This means that the increase in the capital by $1 \%$, will lead to decrease the service requisites by $-1.2 \%$. So, the relation between them is integral. The reason for this maybe is due to the decrease when capital price rise, so the demand derived on the service requisites will be decreased. This is also the case for the cross-demand elasticity between the capital and services requisites, for the demand function on services requisites, was negative too. It was equal to -1.3 . i.e the increase in services requisites with $1 \%$ will decrease capital with $-1.3 \%$. i.e the relation between them, the capital and the services requisites, is integration when the capital price is low then it should be natural to see increase on services requisites with $\mathrm{L} 1 \%$. The partial elasticity of substitution between production elements clarifies that the labor increase $+\mathrm{L}$ with $1 \%$ lead to decrease capital element $-\mathrm{K}$ with certain rate, which is the relative change between capital and labor as a result of the relative change between capital price and labor wage with about $1 \%$, and the same thing happened for all other elements. The partial elasticity of substitution (Allen-Uzawa) between the labor and the capital elements is 0.0009 which means that the increase in capital price value to the labor wage with $1 \%$, the ratio of capital element to the labor wage decreases with $0.0009 \%$, and it is very low ratio. This clarify the decrease in capital demand. The elasticity of substitution between the labor and the commodities requisites, and the capital and commodities requisites with $1 \%$ ratio, the ratio of capital element and labor element to the requisites will also decrease with ratio of $0.10 \%$. Concerning the Allen elasticity of the service commodities, the elasticity of substitution for the labor and commodities was 0.96 . This means that the increase in the labor wage value to the service requisites with a ratio of $1 \%$, the ratio of labor wage to the service requisites decrease with $0.96 \%$. The Allen elasticity value concerned with service requisites and capital is $-1.3 \%$. This means that the increase in the capital value to the service requisites with ratio of $1 \%$ the capital element to the service will increase with $1.3 \%$. It is confirmed that when the capital increase there will be increasing in demand on these commodities. Finally, the Allan partial elasticity of the relation between the service and commodities requisites has the value of 1.03. This means an increase in commodities requisites to the service with $1 \%$ ratio then the ratio of service requisites element to capital will decrease with $1.03 \%$. The Morishima partial elasticity of substitution for production element $(2.27,0.02,2.1,0,06)$. This means that an increase in one of the elements will come with a decrease in the other production element. For example, i.e an increase in capital price will lead to decrease in demand on labor and will agree with the elasticity of Allen-Uzawa in as far as the nature of relation between the two elements. It also reflects less decrease in demand in compare with rising wages. The same table also shows that the Allan partial elasticity and elasticity of demand for some production elements have the values of less than one. This means that the relation in not elastic. According to the results which were achieved, the research found that the companies have the capability of substitution the production elements among each other. In addition, there are many other varieties available to the producers of substitution between production elements. There is strong relation between production elements prices and the total costs. This strong relation was clear in high cost function or production elements shares function. In case of increase in these prices, its contribution shares in the total cost increase. It is found that the relation between labor and capital was of substitution i.e in case of increasing in labor wage there will be increasing in demand on capital. While the relation between labor and requisites is characterized with weakness, maybe it is approaching to have independency between the tow elements. Also, this research shows that the elasticity of self-demand, demand on 
labor and on commodities requisites is not elastic but it was elastic on capital and service requisites. As a result the research recommended to involve the technological development in the production of the companies due to its effect on decreasing the costs and increasing the profits. This would lead to typical use for the capital and to exploit the positive economies of scale. This would help in decreasing the costs average. It is also possible to have wide substitution between some production elements, although this will be subjected to technical factors but there could be substitution inside service and commodity groups. It is necessary to put condensation of production elements with the importance of capital. This study had shown that the capital is more important than the labor to achieve increase in production, making the additional value, decreasing the prices of the production elements, especially the service requisites. The service requisites have a big role in decreasing the share of this resource in the total cost.

\section{REFRENCES}

1-Al-Harthy,M.M.1995.Cost function of riyadh Refinery, M.Sc. Thesis, Department of Economics, Collage of Administrative Sciences ,King Saud University,Riyadh,23(6):88-92

2-Al-Haryhy,M.M.andA.M.Abdl-

Rahman,1996.The Traditional Cost Structures in the Refining Industry in Kingdom Saudi Arabia,Journal of.KingSaudUniversity

,Administrative sciences:9(2):13

3-Ali.I.H and Q. Tami,2018,Estimation of the costing function of barley production in Wasit Governorate ,Mesopotamia.48(3):20-30

4- Allen J. 1,2005,efficiency and economies of scal of large Canadia Banks.Working Paper Bank of Canda.12(4):17-25

5- Al-Quraishi M. ,2006,Measuring economc efficiency in banking institutions. 4:228.

6- Al-Saati.A and M. Al-Osaiami.2009. estimation of the cost function of Islamic and Jeddah.10(7):123-130

7-Arrow.H.B.andB.S.Chenery.and

R.M.Minhas,1966,Capital labor substitution and efficiency review of economics and Statistics.43(4):225-250
8-Asaf, A. and M. H. Wadi,2010,Economics of the arab world. pp:123

9-Asleh, S. M, 2015, Estimaation of Cost and Production Function in the Food Industries sector, M.Sc. Thesis, Department of. Developmen Economic, Colleg Of Commerce Islamic University, Gazy.pp:100

10-Bakhit,H.A.B and S. Fathallah ,2007, The economist,Dar Al-Yazory Scientific

Amman,Jordan,pp:346

11-Bourqbeh,Sh.B,2011,Evaluation of Operational Efficincy of Islamic Banks,Colleg of Economic Sciences Farhat Abbas University,Algeria.pp:115

12- Christensen,L.R and D.W Jorgenson and L.Lou.1973.Transcendental Logarithmic Production Frontiers, Review of Economics and Statistic.pp:212

13-Flempan.F.H,A.A.Diab,1998,Estimation of Air Transport Cost Function of Saudi Arabia Airlines,Department of Economics,Colleg of Management and Economics ,King Abdulaziz University Journal,Saudi Arabia. 3:8

14-Ibtisam.S. 2009,Evalution of the Efficiency of the Algerian Financial System and its Role in Financing the Economy ,M.Sc. Thesis ,Colleg of Economic Sciences, University of Mohammed Khudair ,Bskrah.

15-Ali.H.i,2009,Evalution and competitveness of public agricultural companies in iraq ,Journal of agricultural sciences ,Department of agricultural economics, University of baghdad.3(1):11

16-Makida.A,2007,The Economist University Press, The Algerian.pp:123

17-Saleh.U.S and A.A.Fadel,Evaluation the performance of iraq companies using the model of return property rights . College of Management and Economics, University of Basra .4( 1):12

18-Yahya,M.M, 2008, Use of the sure method in the estimating the system of equally unequual equations fot The Sam company sample ,rafdin developmant Journal,Colleg of Administration and Rconomics, University of Mousl.15( 1):55-40 